\title{
Antioxidant Property and Bactericidal Activity of Linum usitatissimum Seed Essential Oil Nanoemulsion (LSEO-NE) on Staphylococcus aureus
}

\author{
Roghaye Keykhasalar ${ }^{1}$, Masoud Homayouni Tabrizi ${ }^{1,{ }^{*}}$ and Pouran Ardalan ${ }^{2}$ \\ ${ }^{1}$ Department of Biology, Mashhad Branch, Islamic Azad University, Mashhad, Iran \\ ${ }^{2}$ Department of chemistry, Mashhad Branch, Islamic Azad University, Mashhad, Iran \\ "Corresponding author: Department of Biology, Mashhad Branch, Islamic Azad University, Mashhad, Iran. Email: mhomayouni6@gmail.com \\ Received 2020 February 04; Revised 2020 March 29; Accepted 2020 April 09.
}

\begin{abstract}
Background: Linum usitatissimum Seed Essential Oil (LSEO) as an efficient antimicrobial compound contains various types of phytochemicals, such as lignans and phenols.

Objectives: In the current study, we produced LSEO nanoemulsion (LSEO-NE) to study its antioxidant capacity and bactericidal activity against Staphylococcus aureus.

Methods: The LSEO-NE was produced using the ultrasonication method and characterized by Atomic Force Microscopy (AFM), Dynamic Light Scattering (DLS), and Scanning Electron Microscopy (SEM). Then, we measured its antioxidant activity utilizing both ABTS and DPPH tests at four different LSEO-NE concentrations $(200,600,800$, and $1000 \mu \mathrm{g} / \mathrm{mL})$ compared to glutathione. Finally, we evaluated its bactericidal activity on S. aureus by studying Antibiotic Susceptibility Testing (AST) using LSEO-NE-smeared discS compared to non-smeared and kanamycin discs.

Results: The $67.3 \mathrm{~nm}$ droplets of LSEO-NE with PDI of 0.452 exhibited strong antioxidant activity, similar to glutathione, in both ABTS $\left(\mathrm{IC}_{50}=350 \mu \mathrm{g} / \mathrm{mL}\right)$ and DPPH $\left(\mathrm{IC}_{50}=235 \mu \mathrm{g} / \mathrm{mL}\right)$ tests. Moreover, the AST results revealed the significant sensitivity of S. aureus to LSEO-NE-smeared discs when compared to non-smeared and kanamycin discs.

Conclusions: According to the results, LSEO-NE can be applied as a safe, natural, and effective antibiotic for bacterial infections caused by S. aureus in most organs, such as the respiratory system and skin. However, further in vivo studies are required to evaluate the LSEO-NE antibacterial efficiency against other pathogenic S. aureus strains.
\end{abstract}

Keywords: Linum usitatissimum Seed Essential Oil (LSEO), Antioxidant, Antibacterial Activity, Staphylococcus aureus

\section{Background}

Linum usitatissimum (flax), an annual herb from the genus Linum of family Linaceae, grows in Mediterranean and temperate belts. The flax seed essential oil is known as the primordial oil applied in varnishes, bio-insecticides, paints, and herbicides. It contains flavonoids, phenols, and lignins, which can influence cell growth and survival (1, 2). Linum usitatissimum Seed Essential Oil (LSEO) has individual phytochemical components containing lignans, flavonoids, and phenolic acids, which have been approved as strong radical scavenging and antibacterial agents (3).

The medicinal application of essential oils is limited due to their low bio-accessibility and water-solubility. In this regard, various types of influencer tools called drug delivery systems have been utilized to optimize therapeutic efficiency, such as nanoemulsions of nonpolar compounds like herbal essential oils (4). The 20 to $200 \mathrm{~nm}$ hydrophobic or hydrophilic droplets in opposite solutions encapsu- lating either polar or non-polar compounds are called nanoemulsions (5).

Several types of emulsification processes are available based on the amount of consumed energy in the process of droplet formulation, including low (spontaneous) and high (ultrasound-based) energy-consuming methods. The latter method provides nanoscale emulsions by consuming $\sim 10^{8}-10^{10}$ Watt per kilogram $\left(W^{\prime} k^{-1}\right.$ ) energy (6). It is a safe, easy, fast, and cost-effective method for nanoemulsification. The smallest droplets are the best in biological applications due to their improved absorbency, stability, and solubility (7). Currently, nanoemulsions are produced by encapsulating hydrophobic essential oil in a hydrophilic-continuous phase $(8,9)$. These types of nanoemulsions are widely used in the pharmaceutical industry as anticancer, antioxidant, and antimicrobial agents $(10,11)$.

One of the most dangerous bacterial infections is 
caused by Staphylococcus aureus strains, especially in the skin and respiratory system (12). Different types of antibiotics, such as kanamycin, have been introduced for the treatment of such infections (13). However, several undesirable side effects have been reported for kanamycin consumption, such as ototoxic effects (14). Thus, the search for a less toxic and safe compound seems to be required.

\section{Objectives}

This study aimed to prepare LSEO Nanoemulsions (LSEO-NE) and characterize it using Atomic Force Microscopy (AFM), Dynamic Light Scattering (DLS), and Scanning Electron Microscopy (SEM). Then, its antioxidant activity was evaluated, utilizing both ABTS and DPPH tests. Finally, the bactericidal activity of LSEO-NE was investigated against $S$. aureus.

\section{Methods}

\subsection{Material}

We obtained Linum usitatissimum seed essential oil (flaxseed oil, commercially available, Dr. Zarghani, Mashhad, Iran). Nonionic surfactant Tween 80, nutrient broth medium, kanamycin, 2,2-azino-bis-3ethylbenzothiazoline-6-sulfonic acid (ABTS), and 1,1diphenyl-2-picrylhydrazyl (DPPH) were supplied from Sigma-Aldrich (St. Louis, MO). Staphylococcus aureus (ATCC 12228) was purchased from the Pasteur Institute of Iran (Tehran, Iran).

\subsection{LSEO-NE Preparation}

The LSEO-NE was formulated by ultrasonic-based homogenizing of LSE oil and water in the presence of different volumes of nonionic surfactant Tween 80 (3, 6, and 9 $\mathrm{mL})$. The hydrophilic-hydrophobic balance for Tween 80 has been defined at 15 . The sonication process was done under $20 \mathrm{kHz}$ frequency and 750 Watt power for $60 \mathrm{~min}(15$, 16).

\subsection{LSEO-NE Characterization}

The LSEO-NE mean hydrodynamic size (Z-average) was analyzed in three different conditions of surfactant volume (3, 6, and $39 \mathrm{~mL})$, and approved by high-resolution AFM for the smallest LSEO-NE droplets, formed in the presence of $9 \mathrm{~mL}$ surfactant. Moreover, the droplets' morphology was studied by Field Emission Electron Microscopy (FESM) according to the Sun et al. methodology. Briefly, a thin layer of LSEO-NE solution was made by dropping and drying on the microscope slide (gold-coated glass). The prepared slide was used for microscopic studies (17).

\subsection{ABTS and DPPH Antioxidant Tests}

The ability of LSEO-NE in scavenging oxidants and free radicals was measured by two different antioxidant agents, including ABTS and DPPH, based on measuring the absorbance ratio of ABTS and DPPH free radicals against the LSEO-NE nanoemulsion by UV-vis absorption spectroscopy. Briefly, following the Li et al. methodology, ABTS was detected at $734 \mathrm{~nm}$ before and after mixing with LSEO-NE, and according to Kedare et al., DPPH was measured at $517 \mathrm{~nm}$ $(18,19)$. The antioxidant activity (AA\%) of LSEO-NE was estimated using the following formula:

$A A \%=\frac{S A-C A}{C A} \times 100$

In the formula, SA and CA refer to sample absorbance and control absorbance, respectively.

\subsection{Antibiotic Susceptibility Testing (AST)}

The bactericidal activity of LSEO-NE was investigated using the protocol as follows. First, S. aureus ATCC 12228 was inoculated on Mueller-Hinton agar by performing a carpet culture technique. Then, antibiogram discs, including kanamycin, LSEO-NE-smeared, and null discs ( $6 \mathrm{~mm}$ diameter) were preparing and put on the inoculated-culture medium. Finally, culture was done at $37^{\circ} \mathrm{C}$ for 24 hours.

\subsection{Statistical Analysis}

All statistical analyses were performed using SPSS 21 software. The one-way ANOVA test was used to check the significant results. The P values of less than 0.001 were defined as statistically significant.

\section{Results}

\subsection{LSEO-NE Characterization}

Depending on the amount of consumed surfactant, the droplets' Z-average ranged from $67.3 \mathrm{~nm}$ to $82.6 \mathrm{~nm}$. The results showed a significant relationship between the increasing volume of Tween 80 and decreasing nanoemulsion Z-average (P value $\leq 0.001$ ) (Table 1 and Figure 1$)$. We selected nanoemulsion with the smallest droplet size (67.3 $\mathrm{nm}$ ) with appropriate PDI (0.452) for further analysis. Regarding Stetefeld et al., the values of less than 0.7 PDI indicate the mono-distribution process. Therefore, the estimated Z-average values were valid and reliable (20). However, further analyses such as AFM and SEM approved the droplet size and revealed the pseudo-spherical morphology of nanodroplets, respectively (Figure 2A and B). 
A

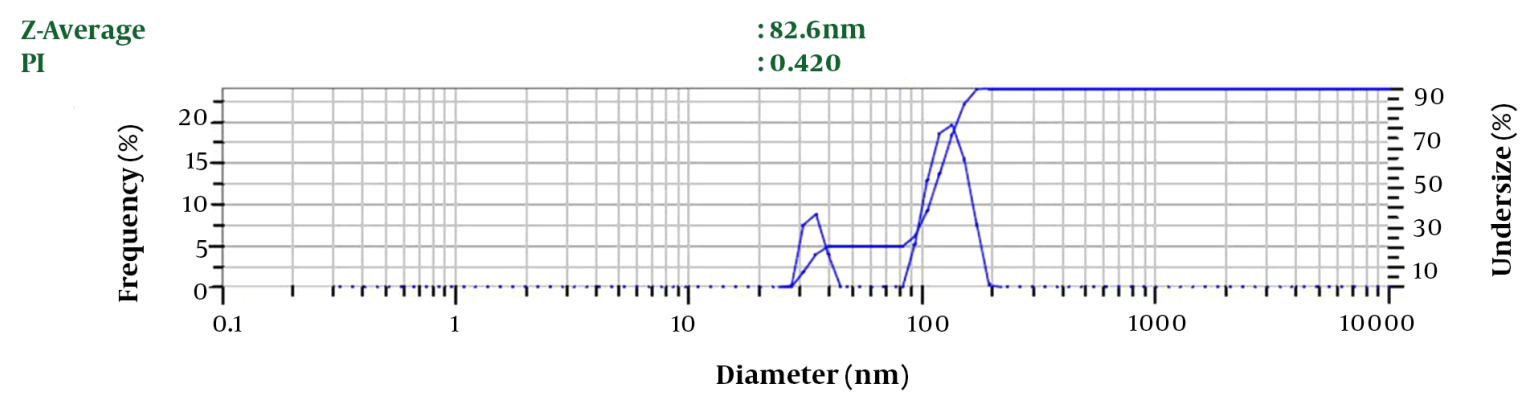

B
Z-Average
PI
$: 71.6 \mathrm{~nm}$
$: 0.309$

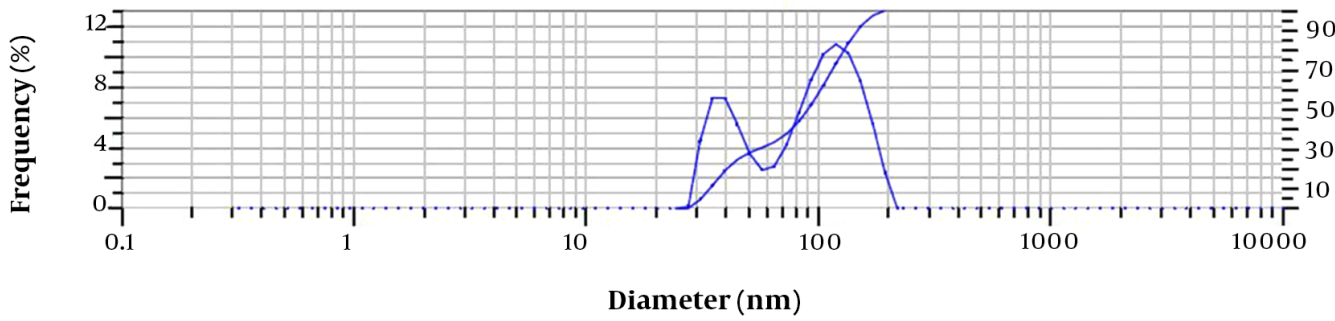

C

Z-Average

PI

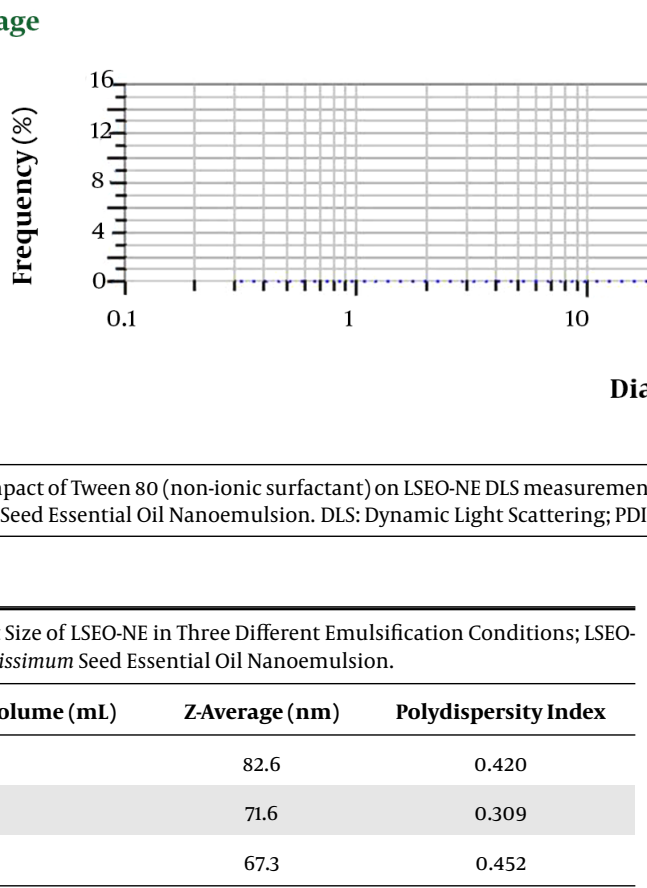
L. usitatissimum Seed Essential Oil Nanoemulsion. DLS: Dynamic Light Scattering; PDI: Polydispersity index.

\subsection{LSEO-NE Antioxidant Activity}

Both ABTS and DPPH tests demonstrated a significant relationship between the increasing doses of LSEO-NE and the decreasing concentrations of ABTS/DPPH free radicals, when compared to glutathione (Figure $3 \mathrm{~A}$ and $\mathrm{B}$ ). The es-

\begin{tabular}{|c|c|c|}
\hline Surfactant Volume $(\mathrm{mL})$ & Z-Average (nm) & Polydispersity Index \\
\hline 3 & 82.6 & 0.420 \\
\hline 6 & 71.6 & 0.309 \\
\hline 9 & 67.3 & 0.452 \\
\hline
\end{tabular}

Int J Infect. 2020; 7(2):e101639.
$: 67.3$

$: 0.452$

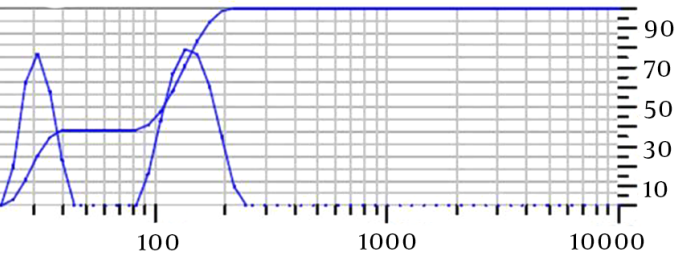

Figure 1. The impact of Tween 80 (non-ionic surfactant) on LSEO-NE DLS measurement data. A, B, and C show the impact of 3, 6, and 9 mL of Tween 80 on particle sizes. LSEO-NE:

timated IC50 was about $350 \mu \mathrm{g} / \mathrm{mL}$ and $235 \mu \mathrm{g} / \mathrm{mL}$ in the ABTS and DPPH assays, respectively. The results revealed the strong antioxidant activity of LSEO-NE, which seemed to make them safe for even in-vivo applications. However, several types of in-vivo studies need to be designed to verify the toxic potential.

\subsection{Bactericidal Activity of LSEO-NE}

The bacterial growth pattern in the presence of antibiogram discs exhibited a significant antibiotic sensitivity in bacteria around the LSEO-NE-smeared disc compared to negative and positive (kanamycin) discs (Figure 4). It was detectable regarding the presence of an inhibited growth zone around the disc (transparent ring). However, several 

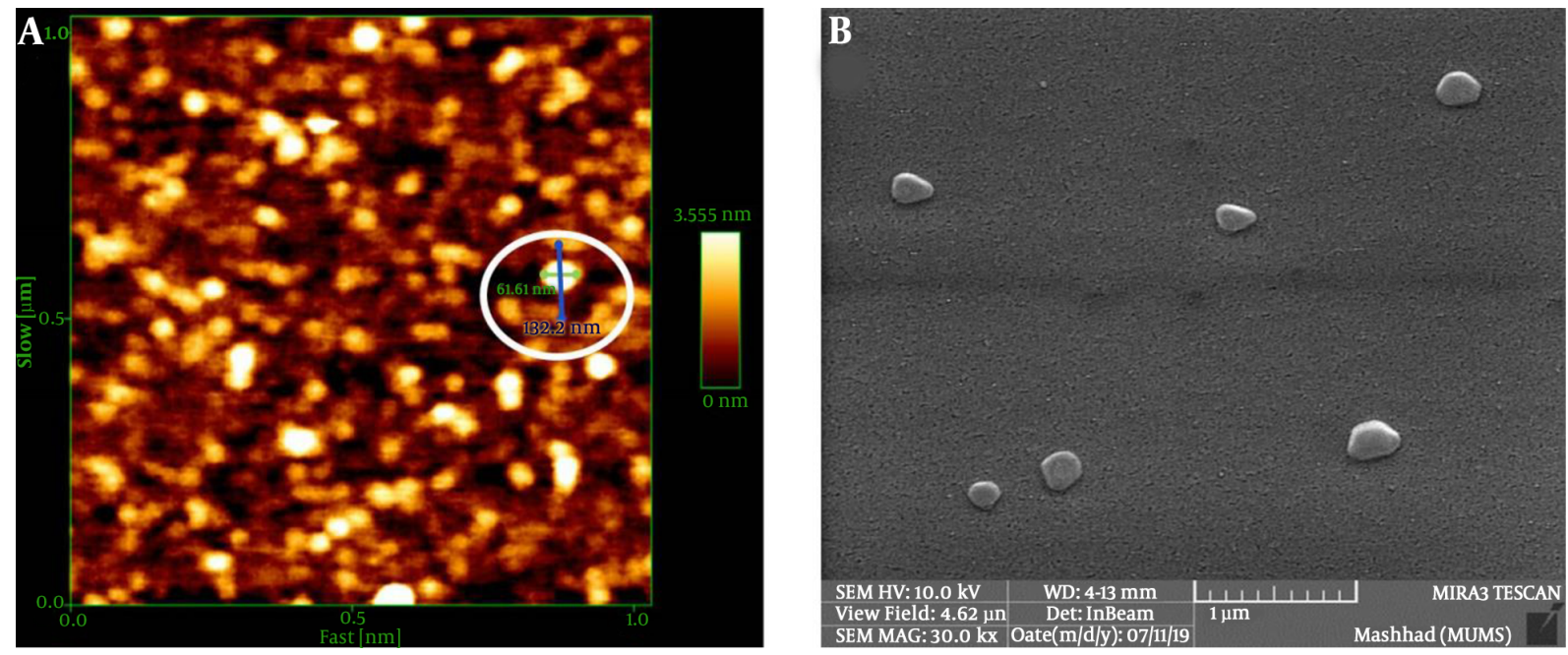

Figure 2. The LSEO-NE size characterization. A: AFM results; the brilliant circle shows the nanoemulsion diameter (61.61 nm) (green line and number) while the blue line and the number indicate the length of the line. B: SEM image of LSEO-NE droplets; pseudo-spherical droplets are detected at the agglomerated size, which may be due to the SEM preparation process. LSEO-NE: L. usitatissimum Seed Essential Oil Nanoemulsion; AFM: Atomic Force Microscopy; SEM: Scanning Electron Microscopy.

A

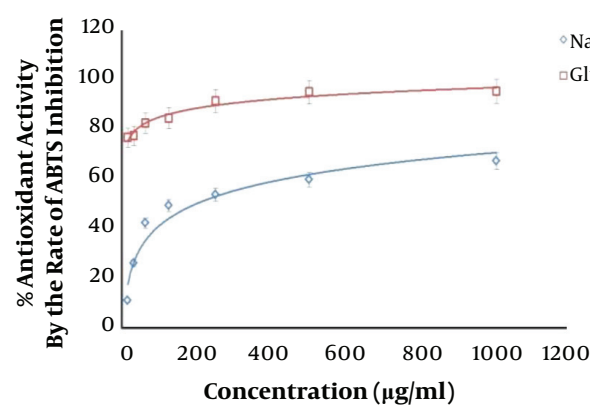

B

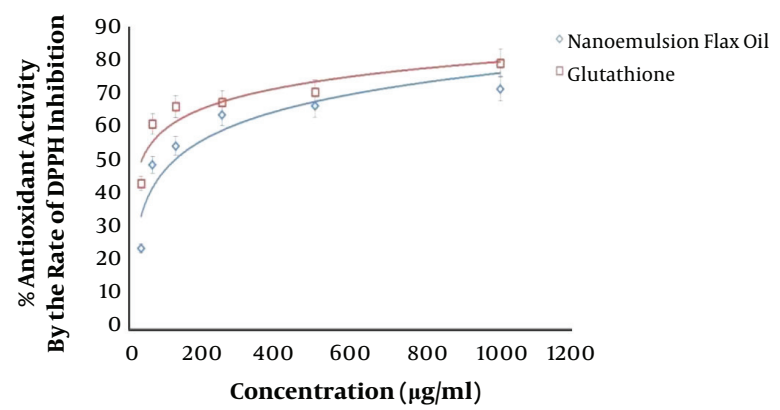

Figure 3. The LSEO-NE antioxidant activity. A: Refers to the \% antioxidant activity by the rate of ABTS inhibition, and shows the IC ${ }_{50}$ of LSEO-NE ( $350 \mu \mathrm{g} / \mathrm{mL}$ ) in the inhibition of ABTS free radicals. B: Refers to the \% antioxidant activity by the rate of DPPH inhibition, and shows the IC ${ }_{50}$ of LSEO-NE $(235 \mu \mathrm{g} / \mathrm{mL})$ in the inhibition of DPPH free radicals. LSEO-NE: L. usitatissimum Seed Essential Oil Nanoemulsion.

bacterial strains and further antimicrobial tests such as the Minimum Inhibitory Concentration (MIC) test is required to define the specificity and strength of its antibiotic activity.

\section{Discussion}

In this study, we used $L$. usitatissimum essential oil (flaxseed essential oil) to prepare nanoemulsion using ultrasonication. Then, we characterized it for size and assessed its antioxidant and antibacterial efficacies. Linum usitatissimum (flax) has been widely used as an effective natural therapeutic agent for various types of disorders, such as inflammation, blood pressure, and acne (3). To the best of our knowledge, this is the first study producing nanoemulsions of flaxseed essential oil for use to evaluate the antioxidant capacity and bactericidal activity against $S$. aureus strains. We produced nanoemulsion with pseudospherical droplets containing L. usitatissimum Seed Essential Oil (LSEO-NE) in $67.3 \mathrm{~nm}$ sizes (Figures 1 and 2) and showed their strong antioxidant activity (Figure 3). Moreover, its bactericidal property was measured by the AST method against $S$. aureus. The results approved the remarkable antibiotic property of LSEO-NE (Figure 4).

Staphylococcus aureus, a Gram-positive facultative anaerobic microbiota member, is often found on the skin and the upper respiratory tract. It can also act as an opportunistic pathogen in skin infections (abscesses), 


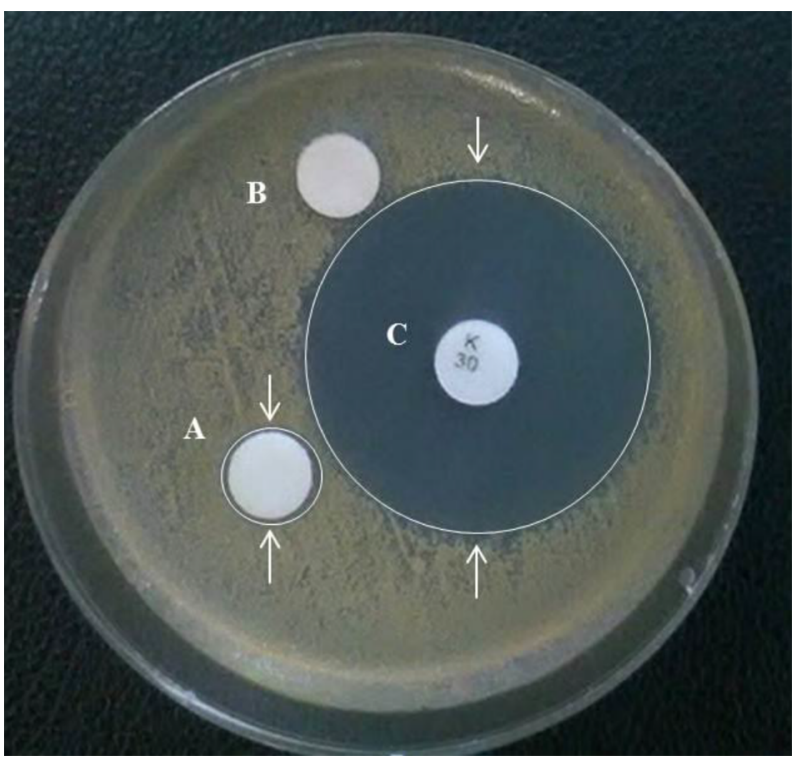

Figure 4. The LSEO-NE bactericidal activity. The image exhibits cultured S. aureus bacteria on Mueller-Hinton agar medium and reveals their sensitivity to the LSEONE-smeared disc (A) compared to negative (B) and positive (kanamycin) (C) control antibiogram discs. LSEO-NE: L. usitatissimum Seed Essential Oil Nanoemulsion. The white arrows indicate the bactericidal zone of discs.

respiratory infections (sinusitis), and poisoned food. Staphylococcal infections are considered as common lifethreatening disorders. Most pathogenic S. aureus strains are resistant to antibiotics, such as Methicillin-resistant $S$. aureus (MSRSA). The prescribed antibiotics such as penicillin, cephalosporin, clindamycin, vancomycin, etc. have potentially various types of side effects. Moreover, there are no vaccines for $S$. aureus yet to be approved (21-23). Therefore, the investigation of alternative natural and safe antibiotics is ongoing by microbiologists.

Various types of plant essential oils and extracts have been recognized as antioxidants and antibiotics such as Lavandula (Angustifolia), Thymus (Vulgaris), peppermint (Mentha), Cajuput, Cinnamon, Clove, Eucalyptus, Sage (Salvia officinalis), and L. usitatissimum (24-32). The in vivo studies have approved the antibacterial activity of L. usitatissimum nonessential oils against bacterial strains such as $S$. aureus, E. coli, and Streptococcus agalactiae, and they were effective in bovine mastitis treatment (32). We investigated the bactericidal activity of L. usitatissimum Seed Essential Oil (LSEO) as a nanoemulsion delivery system against $S$. aureus. The presence of phenols, lignin, and flavonoids has made LSEO an exclusive phytochemical complex affecting cell growth and survival (2). It has the potential to be more efficient if encapsulated with amphiphilic molecules in nanoemulsion. Two main compounds of flaxseed essential oil, including unsaturated fatty acids and lignin are re- sponsible for antibacterial activities $(33,34)$. Making the essential oils in the form of nanoemulsion causes the oil constitutes to become more stable with better efficiency (35).

Nanoemulsions as suitable drug delivery systems have shown a promising horizon in medicine for prevention and/or treatment purposes because of their ability to be more absorbable and bio-compatible, which are the two main important properties required in pharmaceutical approaches (36). In this regard, depending on their contents, they have been used to deliver their contents more efficiently with fewer possible side effects as antiinflammatory, antioxidant, and antibacterial compounds (37-39). The eucalyptus, neem, thyme, lemongrass, and clove essential oils are among the plant essential oils used in nanoemulsion delivery systems (37, 40-44).

The lignans repository consists of the main polyphenolic compounds in L. usitatissimum, which are prominent antioxidant compounds due to their potential of free radical scavenging (45). In the current study, this was approved by decreasing ABTS and DPPH free radicals with increasing doses of LSEO-NE (Figure 3). Flavonoids, as natural antibiotics, and phenolic acids of LSEO are the main components responsible for its antibacterial activity $(46,47)$. Structural heterocyclic N/O, alkylamino chains, and phenyl groups can increase the flavonoids activity and make them efficient in inhibiting the bacterial DNA replication, biofilm formation, energy metabolism, and member porin function. Moreover, flavonoids can lead to a significant alteration in membrane permeability (47). In this regard, the transparent ring around LSEO-NE-smeared antibiogram discs confirmed the induction of LSEO-NE sensitivity in S. aureus, which seemed to be affected by flavonoids and phenolic acids synergistically (Figure 4). However, further complementary studies are required to clarify the bactericidal mechanisms. The antioxidant activity of LSEO-NE makes it safe for treating bacterial infections.

\subsection{Conclusion}

According to the results, the nanoemulsion of $L$. usitatissimum seed essential oil can significantly scavenge radicals and induce an inhibitory effect on the $S$. aureus growth and proliferation cycle. In other words, the antioxidant activity of LSEO-NE, along with its bactericidal property and bio-accessibility makes LSEO-NE a suitable and safe antibiotic. Therefore, it can be used as a safe, natural, and efficient anti-S. aureus agent. However, further in-vivo and in-vitro studies are required to evaluate the LSEO-NE bactericidal efficiency against other pathogenic $S$. aureus strains. 


\section{Footnotes}

Authors' Contribution: Study concept and design: M. H. and P. A.; Analysis and interpretation of data: M. H, and R. K, and P. A; Drafting of the manuscript: $\mathrm{M}$. H; Critical revision of the manuscript for important intellectual content: R. K. and M. H.; Statistical analysis: M. H.

Conflict of Interests: No conflict of interest was declared. Ethical Approval: ir.iau.mshd.rec.1398.027.

Funding/Support: This study was supported by the Islamic Azad University of Mashhad.

\section{References}

1. Amin T, Thakur M. Linum usitatissimum L.(Flaxseed)-A multifarious functional food. Online International Interdisciplinary Research Journal. 2014;4(1):220-38.

2. Hussain S, Anjum FM, Butt MS, Khan MI, Asghar A. Physical and sensoric attributes of flaxseed flour supplemented cookies. Turkish Journal of Biology. 2006;30(2):87-92.

3. Banerjee K, Thiagarajan P. Linum usitatissimum L.(Flax) plant and its seed oil a review. JCHPS. 2015;8(4):623-8.

4. Nishitani Yukuyama M, Tomiko Myiake Kato E, Lobenberg R, Araci Bou-Chacra N. Challenges and future prospects of nanoemulsion as a drug delivery system. Current pharmaceutical design. 2017;23(3):495508.

5. Solans C, Izquierdo P, Nolla J, Azemar N, Garcia-Celma MJ. Nanoemulsions. Current opinion in colloid \& interface science. 2005;10(34):102-10.

6. Date AA, Desai N, Dixit R, Nagarsenker M. Self-nanoemulsifying drug delivery systems: formulation insights, applications and advances. Nanomedicine. 2010;5(10):1595-616.

7. Mahdi Jafari S, He Y, Bhandari B. Nano-emulsion production by sonication and microfluidization-a comparison. International Journal of Food Properties. 2006;9(3):475-85.

8. Sarker DK. Engineering of nanoemulsions for drug delivery. Current drug delivery. 2005;2(4):297-310.

9. Wasan KM. Role of lipid excipients in modifying oral and parenteral drug delivery: Basic principles and biological examples. John Wiley \& Sons; 2007.

10. Borthakur P, Boruah PK, Sharma B, Das MR. 5 - Nanoemulsion: preparation and its application in food industry. In: Grumezescu AM, editor. Emulsions. Academic Press; 2016. p. 153-91. doi: 10.1016/B978-0-12804306-6.00005-2.

11. Jaiswal M, Dudhe R, Sharma PK. Nanoemulsion: an advanced mode of drug delivery system. 3 Biotech. 2015;5(2):123-7. doi: 10.1007/s13205014-0214-0. [PubMed: 28324579]. [PubMed Central: PMCPmc4362737].

12. Tong SY, Davis JS, Eichenberger E, Holland TL, Fowler VG. Staphylococcus aureus Infections: Epidemiology, Pathophysiology, Clinical Manifestations, and Management. Clinical Microbiology Reviews. 2015;28(3):603-61. doi: 10.1128/cmr.00134-14.

13. Pengov A, Ceru S. Antimicrobial drug susceptibility of Staphylococcus aureus strains isolated from bovine and ovine mammary glands. Journal of dairy science. 2003;86(10):3157-63.

14. Wrześniok D, Rok J, Beberok A, Rzepka Z, Respondek M, Pilawa B, et al. Kanamycin induces free radicals formation in melanocytes: An important factor for aminoglycosides ototoxicity. Journal of cellular biochemistry. 2019;120(2):1165-73.

15. Ghosh V, Saranya S, Mukherjee A, Chandrasekaran N. Cinnamon oil nanoemulsion formulation by ultrasonic emulsification: investiga- tion of its bactericidal activity. Journal of nanoscience and nanotechnology. 2013;13(1):114-22.

16. Qian C, McClements DJ. Formation of nanoemulsions stabilized by model food-grade emulsifiers using high-pressure homogenization: factors affecting particle size. Food Hydrocolloids. 2011;25(5):1000-8.

17. Sun H, Liu K, Liu W, Wang W, Guo C, Tang B, et al. Development and characterization of a novel nanoemulsion drug-delivery system for potential application in oral delivery of protein drugs. International journal of nanomedicine. 2012;7:5529-43. doi: 10.2147/IJN.S36071. [PubMed: 23118537].

18. Li P, Huo L, Su W, Lu R, Deng C, Liu L, et al. Free radical-scavenging capacity, antioxidant activity and phenolic content of Pouzolzia zeylanica. Journal of the Serbian Chemical Society. 2011;76(5):709-17.

19. Kedare SB, Singh RP. Genesis and development of DPPH method of antioxidant assay. Journal of food science and technology. 2011;48(4):41222. doi: 10.1007/s13197-011-0251-1. [PubMed: 23572765].

20. Stetefeld J, McKenna SA, Patel TR. Dynamic light scattering: a practical guide and applications in biomedical sciences. Biophysical reviews. 2016;8(4):409-27.

21. Redi D, Raffaelli CS, Rossetti B, De Luca A, Montagnani F. Staphylococcus aureus vaccine preclinical and clinical development: current state of the art. New Microbiol. 2018;41(3):208-13. [PubMed: 29874390]

22. Cunha BA. Antibiotic side effects. Med Clin North Am. 2001;85(1):149-85. doi: 10.1016/s0025-7125(05)70309-6. [PubMed: 11190350].

23. Rayner C, Munckhof WJ. Antibiotics currently used in the treatment of infections caused by Staphylococcus aureus. Intern Med J. 2005;35 Suppl 2:S3-16. doi: 10.1111/j.1444-0903.2005.00976.x. [PubMed: 16271060].

24. Blažeković B, Yang W, Wang Y, Li C, Kindl M, Pepeljnjak S, et al. Chemical composition, antimicrobial and antioxidant activities of essential oils of Lavandula $\times$ intermedia 'Budrovka'and L. angustifolia cultivated in Croatia. Industrial Crops and Products. 2018;123:173-82.

25. Mancini E, Senatore F, Del Monte D, De Martino L, Grulova D, Scog namiglio M, et al. Studies on Chemical Composition, Antimicrobial and Antioxidant Activities of Five Thymus vulgaris L. Essential Oils. Molecules. 2015;20(7):12016-28. doi:10.3390/molecules200712016. [PubMed: 26140436]. [PubMed Central: PMCPmc6332365].

26. Stringaro A, Colone M. Antioxidant, Antifungal, Antibiofilm, and Cytotoxic Activities of Mentha spp. Essential Oils. Medicines. 2018;5(4) doi: 10.3390/medicines5040112. [PubMed: 30347861].

27. Dahiya P. Evaluation of in vitro antimicrobial potential and phytochemical analysis of spruce, cajeput and jamrosa essential oil against clinical isolates. International Journal of Green Pharmacy (IJGP). 2016;10(1).

28. Kawatra P, Rajagopalan R. Cinnamon: Mystic powers of a minute ingredient. Pharmacognosy Res. 2015;7(Suppl 1):S1-6. doi: 10.4103/0974-8490.157990. [PubMed: 26109781]. [PubMed Central PMCPmc4466762].

29. Cui H, Zhang C, Li C, Lin L. Antimicrobial mechanism of clove oil on Listeria monocytogenes. Food control. 2018;94:140-6.

30. Sebei K, Sakouhi F, Herchi W, Khouja ML, Boukhchina S. Chemical composition and antibacterial activities of seven Eucalyptus species essential oils leaves. Biol Res. 2015;48:7. doi: 10.1186/0717-6287-48-7. [PubMed: 25654423]. [PubMed Central: PMCPmc4417289].

31. Cutillas AB, Carrasco A, Martinez-Gutierrez R, Tomas V, Tudela J. Salvia officinalis L. Essential Oils from Spain: Determination of Composition, Antioxidant Capacity, Antienzymatic, and Antimicrobial Bioactivities. Chem Biodivers. 2017;14(8). doi: 10.1002/cbdv.201700102. [PubMed: 28477412].

32. Kaithwas G, Mukerjee A, Kumar P, Majumdar DK. Linum usitatissimum (linseed/flaxseed) fixed oil: antimicrobial activity and efficacy in bovine mastitis. Inflammopharmacology. 2011;19(1):45-52.

33. Zuk M, Dorotkiewicz-Jach A, Drulis-Kawa Z, Arendt M, Kulma A, Szopa J. Bactericidal activities of GM flax seedcake extract on pathogenic bacteria clinical strains. BMC biotechnology. 2014;14(1):70. 
34. Fadzir UA, Darnis DS, Mustafa BE, Mokhtar KI. Linum usitatissimum as an antimicrobial agent and a potential natural healer: A review. Archives of Orofacial Science. 2018;13(2).

35. Prakash A, Baskaran R, Nithyanand P, Vadivel V. Effect of Nanoemulsification on the Antibacterial and Anti-biofilm Activities of Selected Spice Essential Oils and Their Major Constituents Against Salmonella enterica Typhimurium. Journal of Cluster Science. 2019:1-13.

36. Sharma N, Bansal M, Visht S, Sharma PK, Kulkarni GT. Nanoemulsion: A new concept of delivery system. Chronicles of Young Scientists. 2010;1(2):2.

37. Ziani K, Chang Y, McLandsborough L, McClements DJ. Influence of surfactant charge on antimicrobial efficacy of surfactant-stabilized thyme oil nanoemulsions. Journal of agricultural and food chemistry. 2011;59(11):6247-55.

38. Farshi P, Tabibiazar M, Ghorbani M, Hamishehkar H. Evaluation of antioxidant activity and cytotoxicity of cumin seed oil nanoemulsion stabilized by sodium caseinate-guar gum. Pharm. 2017.

39. Yen C, Chen Y, Wu M, Wang C, Wu Y. Nanoemulsion as a strategy for improving the oral bioavailability and anti-inflammatory activity of andrographolide. International journal of nanomedicine. 2018;13:66980. doi: 10.2147/IJN.S154824. [PubMed: 29440893].

40. Sakulku U, Nuchuchua O, Uawongyart N, Puttipipatkhachorn S, Soottitantawat A, Ruktanonchai U. Characterization and mosquito repellent activity of citronella oil nanoemulsion. International journal of pharmaceutics. 2009;372(1-2):105-11.

41. Anjali $\mathrm{CH}$, Sharma $\mathrm{Y}$, Mukherjee A, Chandrasekaran N. Neem oil (Azadirachta indica) nanoemulsion-a potent larvicidal agent against Culex quinquefasciatus. Pest management science. 2012;68(2):158-63.

42. Pant M, Dubey S, Patanjali PK, Naik SN, Sharma S. Insecticidal activity of eucalyptus oil nanoemulsion with karanja and jatropha aqueous filtrates. International Biodeterioration \& Biodegradation. 2014;91:11927.

43. Salvia-Trujillo L, Rojas-Graü A, Soliva-Fortuny R, Martín-Belloso O. Physicochemical characterization of lemongrass essential oil-alginate nanoemulsions: effect of ultrasound processing parameters. Food and Bioprocess Technology. 2013;6(9):2439-46.

44. Anwer MK, Jamil S, Ibnouf EO, Shakeel F. Enhanced antibacterial effects of clove essential oil by nanoemulsion. Journal of oleo science. 2014:ess13213.

45. Hu C, Yuan YV, Kitts DD. Antioxidant activities of the flaxseed lignan secoisolariciresinol diglucoside, its aglycone secoisolariciresinol and the mammalian lignans enterodiol and enterolactone in vitro. Food and chemical toxicology. 2007;45(11):2219-27.

46. Cueva C, Moreno-Arribas MV, Martin-Alvarez PJ, Bills G, Vicente MF, Basilio A, et al. Antimicrobial activity of phenolic acids against commensal, probiotic and pathogenic bacteria. Res Microbiol. 2010;161(5):372-82. doi: 10.1016/j.resmic.2010.04.006. [PubMed: 20451604].

47. Xie Y, Yang W, Tang F, Chen X, Ren L. Antibacterial activities of flavonoids: structure-activity relationship and mechanism. Curr Med Chem. 2015;22(1):132-49. doi:10.2174/0929867321666140916113443. [PubMed: 25245513] 